\title{
White Spleen in Hairy Cell Leukemia - Case Report and Review of the Literature
}

\author{
Vladimir Milosavljević1, Boris Tadić²*, Nikola Grubor², Maja Dimić Ćumičª, Slavko Matić \\ ${ }^{1}$ General Hospital Stefan Visoki, Smederevska Palanka \\ ${ }^{2}$ Clinic for Digestive Surgery of the CCS- First Surgical Clinic, Belgrade \\ ${ }^{3}$ Clinical Centre of Serbia, Department of Histopathology, Belgrade, Serbia
}

*Corresponding Author: Boris Tadić, Clinic for Digestive Surgery of the CCS- First Surgical Clinic, Belgrade, Email: tadicboris@yahoo.com

\begin{abstract}
Hairy cell leukemia is a malignant chronic lymphoproliferative disease that covers for about $2 \%$ of all leukemia and occurs four times more often in males. It is most often manifested by splenomegaly. Splenomegaly often becomes symptomatic and manifests as pain in the epigastrium and feeling of flatulence and discomfort in the abdomen. Cladribine and Pentostatin are purine analogues and they represent the first line in the treatment of this disease. Splenectomy is applied in patients with massive symptomatic splenomegaly, severe pancytopenia, as well as a temporary measure in pregnant women when symptomatology is expressed. In our work, we present a patient who experienced a relapse of the disease after two cycles of chemotherapy, as confirmed by biopsies of the bone marrow. From this case can be concluded that even in the era of the use of purine analogues, splenectomy can be of great benefit in the treatment, and determinant of its further outcome for those affected by Hairy cell leukemia.
\end{abstract}

Keywords: spleen, splenomegaly, splenectomy, hairy cell leukemia

\section{INTRODUCTION}

The first researches by the haematologist and the first indications regarding Hairy cell leukemia date back to the 1923. Since then, there have been numerous studies related to this disease and described in the literature $(1,2)$. In 1958. Bouroncle and associates described the leukemic reticuloendotheliosis as a separate entity with a typical (Hailary cell) cell appearance (3).

Hairy cell leukemia (HCL) is a malignant chronic lymphoproliferative disease that covers $2 \%$ of all leukemia and occurs four times more often in males than in females. The average age of patients diagnosed with this disease is about 55 years (4.5). The disease is manifested by pancytopenia, absence of peripheral lymphadenopathy, enlarged spleen and often absolute monocytopenia. Peripheral blood contains mature B cells with voluminous cytoplasmic projections that resemble hairs. Histologically, HCL cells biopsied from the bone marrow have a cytoplasm that surrounds the nucleus and that way resembles an egg (6).

The most common manifestation of this disease is splenomegaly and occurs in about $96 \%$ of

ARC Journal of Clinical Case Reports patients. Often, splenomegaly becomes symptomatic and manifests as pain in the epigastrium and feeling of flatulence and discomfort in the stomach $(7,8)$.

Until 1984, splenectomy was the method of choice in the treatment of this disease (9). The start of administration of purine analogues in the treatment of HCL was a revolutionary treatment, with a total response of $85 \%$ of patients and survival up to 15 years without a progression (10.11)

Cladribine and Pentostatin, 2 analogues of purine, are the first line in the treatment of HCL. They are equally effective in encouraging and maintaining of remission. Thanks to its favorable toxicity profile, most hematologists consider that Cladribin is the first line of chemotherapy. Interferon alfa is an option for treatment of this disease during pregnancy, when the treatment is justified. It can also be used as initial treatment in patients with severe pancytopenia or an active infection, in order to improve blood test results and to allow further therapy of purine analogues $(12,13,14)$.

Splenectomy is applied in a patients with massive symptomatic splenomegaly, severe pancytopenia 
due to cell sequestration, as well as a temporary measure in pregnant women when symptomatology is expressed (14).

In our work, we present a patient who experienced a relapse of the disease after two cycles of chemotherapy, as confirmed by biopsies of the bone marrow. Because of massive symptomatic splenomegaly, leukocytopenia and, thrombocytopenia, the consilium, consisted of surgeons and hematologist, decided to perform a splenectomy.

\section{CASE REPORT}

61 years old patient was admitted to the Clinic for Digestive Surgery - First Surgical Clinic, Clinical Center of Serbia, due to pains in the upper parts of the abdomen, feeling of flatulence, weight and discomfort in the abdomen.

At the admission, we discover that his enlarged spleen was diagnosed 16 years ago, when he was also supposed to have a bone marrow biopsy to which he did not go, and hasn't report to a doctor since then. His first admission to our institution was at the end of 2014 as an emergency case due to abdominal pain and the presence of splenomegaly. After initial diagnostics, he was transferred to the Clinic for Hematology where he was diagnosed with Hairy Cell Leukemia and ordinated with chemotherapy (Cladribine). After 6 months, a control biopsy of the bone marrow showed a significant reduction in bone marrow infiltration from $40 \%$ to $10 \%$. In July 2015, he got another cycle of the (Cladribine) chemotherapy. The bone marrow biopsy in january 2016 detected a complete haematological remission of the disease in a bone marrow, but there was still a splenomegaly with expressed symptoms. The value of the platelets at the admission to our Clinic were $38 \times 10^{9} / \mathrm{L}$. Computerized tomography (CT) confirmed the previous finding of splenomegaly. The length of the spleen in the cranial - caudal direction (longitudinal diameter) was $29.09 \mathrm{~cm}$ (Figure 1), while its transversal diameter was $21.81 \mathrm{~cm}$ (Figure 2). Due to the existence of a massive splenomegaly $(>20 \mathrm{~cm}$ in the cranial - caudal direction) we decided for the classic splenectomy. After surgery, the weight of the spleen was $1950 \mathrm{gr}$. The macroscopic preparation of the spleen was largely covered with a lightcolored hyaline capsule with a thickness of 5-15 mm (Figure 3).

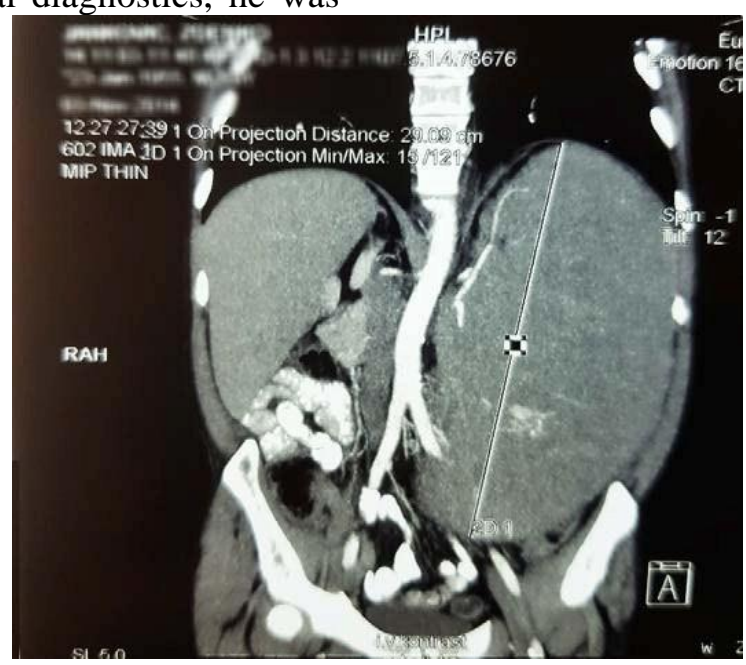

Figure1. Preoperative imaging (CT), Craniocaudal diameter of the spleen

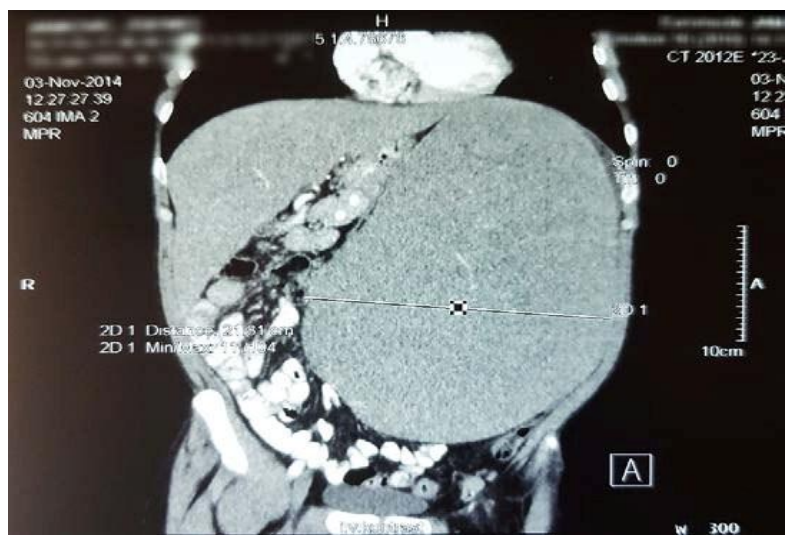

Figure2. Preoperative imaging $(C T)$, transfersal diametar of the spleen 


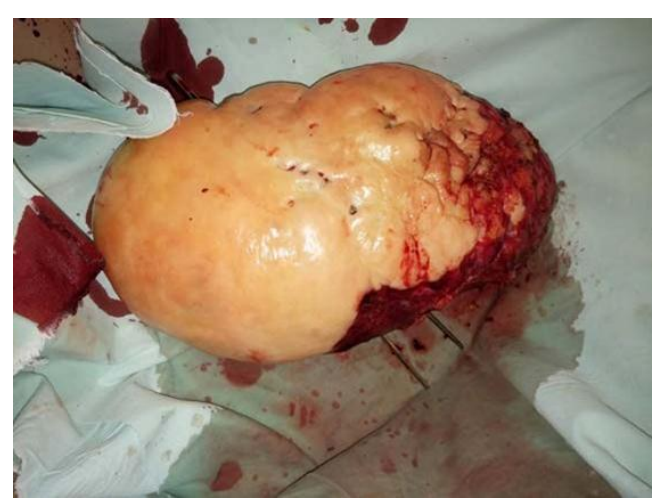

Figure3. The macroscopic preparation of the spleen

Histopathological examination found that splenic architecture was changed to the account of highly expanded red pulp with very rare white pulp residues, and that corresponds to infiltrative leukemic infiltration. This examination also the presence of Residual splenic disease in hairy cell leukaemia after treatment with chemotherapy
(Cladribin). The infiltrates are confined to the red pulp (Figure 4). And Hyaline perisplenitis known as "icing sugar spleen" with capsule thickening ranging 5 to $15 \mathrm{~mm}$ in this patient. Hairy cell infiltrate and blood lakes are seen in splenic parenchyma (Figure 5).

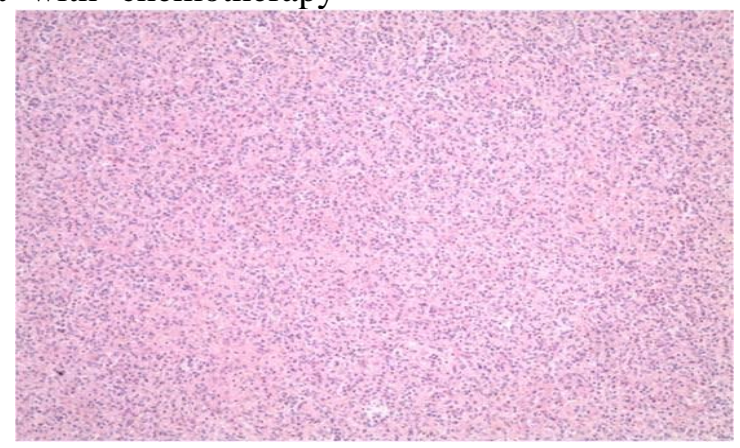

Figure4. The infiltrates are confined to the red pulp

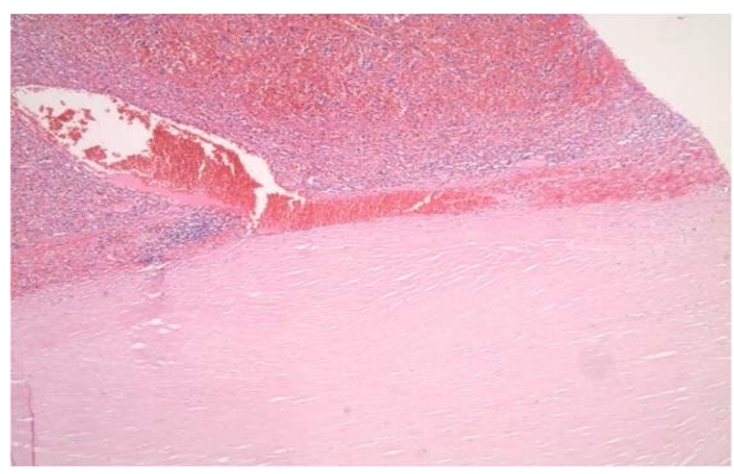

Figure5. Hairy cell infiltrate and blood lakes are seen in splenic parenchyma

Additional immunohistochemical examination confirmed strong, diffuse immunoreactivity for
CD20 (Figure 6). And Immunoreactivity for DAB 44 in splenic hairy cell infiltrate (Figure 7).

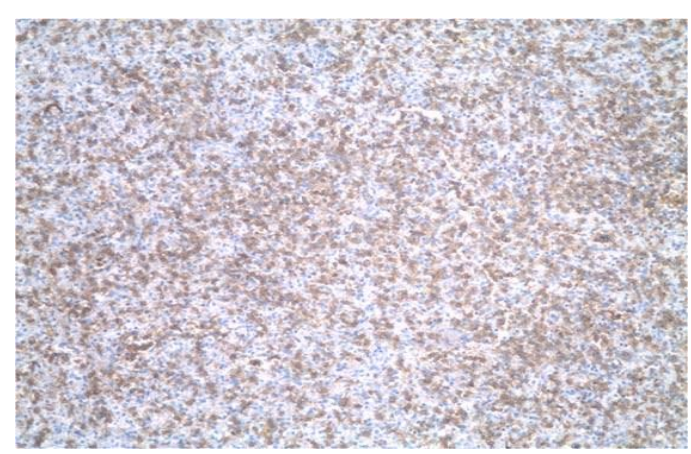

Figure6. Immunohistochemical examination, diffuse immunoreactivity for CD20 


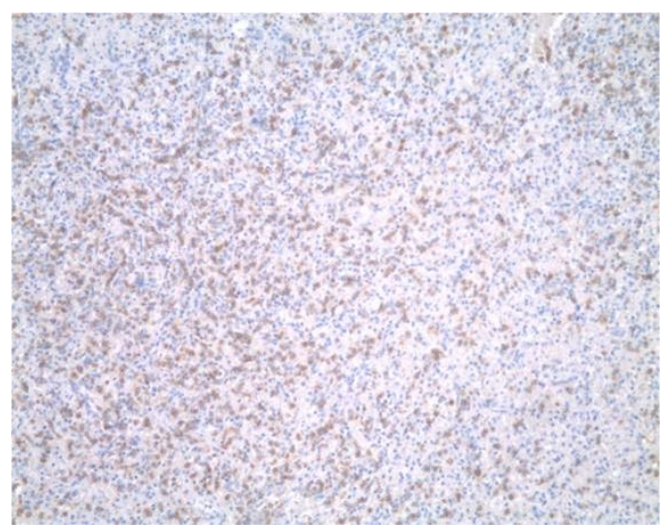

Figure7. Immunohistochemical examination, immunoreactivity for DAB 44 in splenic hairy cell infiltrate

\section{DISCUSSION}

Introduction of purine analogues in the treatment of HCL significantly contributed to improving the patients' survival. In some HCL patients, a long perennial remission can be achieved only with the usage of the purine analogues and without additional therapy (10).

Some authors believe that the length of the disease-free interval is related to achieving a complete response to therapy $(15,16)$. Although Hair Cell Leukemia is an incurable disease, with current therapy, patients can achieve permanent remission without further continuous application of therapy, except in cases of symptomatic relapse (17).

Despite the complete therapeutic response after two cycles of chemotherapy, as confirmed by biopsies of the bone marrow, a permanent splenomegaly remained with pronounced symptoms. By agreement with a surgeon and hematologist, the consilium decided to perform splenectomy. Histopathological examination and immunohistochemical verification confirmed the residual HCL in the spleen. It is not clear if splenomegaly would have spontaneously regress anyway, but after a histopathological examination, it turned out that performing of splenectomy as a strategy proved to be the real therapeutic option.

Patients with complete therapeutic response should have hemoglobin $>110 \mathrm{~g} / \mathrm{L}$, no additional transfusion, platelets> $100 \mathrm{x} \quad 10^{9} / \mathrm{L}$ and neutrophils $>1500 / \mu \mathrm{L}$ (18).

After surgery, and just before hospital release, the patient we operated on had hemoglobin $108 \mathrm{~g}$ / L, platelets $318 \times 10^{9} / \mathrm{L}$ and neutrophils $2100 /$ $\mu \mathrm{L}$.

In patients with HCL, the most common cause is infection. These patients have neutrophilia and monocytopenia, so bacterial, viral and opportunistic infections are expected. Purine analogues provide long-term suppression of immune system cells and induce prolonged neutropenia (19).

It is very important to inform and educate patients about infections prevention. The results of the use of specific preventive options has not been confirmed in some controlled studies, but the practice differs from patient to patient, thus the strategies of prevention and treatment vary $(18,20)$.

After splenectomy, antibiotic prophylaxis, as well as postoperative vaccination, were performed in accordance with the current directives and guidelines for the treatment and prevention of postsplenectomy infections.

After surgery, the patient is in remission for 2 years. His period of monitoring and remission continues.

\section{CONCLUSION}

Although splenectomy does not represent the first measure of treatment of HCL, from this case can be concluded that even in the era of the use of purine analogues, splenectomy can be of great benefit in the treatment and a determinant of it's success. From the literature can be concluded that HCL has many unusual manifestations of the disease and it is necessary to continuously monitor and improve the guidelines and strategies for the treatment, and guidelines should also be of great benefit in improving the treatment and should not be used for refusal of the necessary diagnostic and therapeutic treatment options.

\section{REFERENCES}

[1] Ewald O. Die leukamische reticuloendotheliose. Dtsch Arch Klin Med 1923;142:222e8

[2] Fieschi A. Istioleucemia. Haematologica 1942; 24:751e74.

[3] Bouroncle BA, Wiseman BK, Doan CA. Leukemic reticuloendotheliosis. Blood 1958;13(7):609e30.

[4] Mey U, Strehl J, Gorschlüter M, Ziske C, Glasmacher A, Pralle H, et al. Advances in the 
treatment of hairy-cell leukaemia. Lancet Oncol. 2003;4:86-94.

[5] Jain P, Pemmaraju N, Ravandi F. Update on the biology and treatment options for hairy cell leukemia. Curr Treat Options Oncol. 2014;15:187-209.

[6] Pande P, Yelikar BR, Kumar MU. A hairy cell leukaemia variant - a rare case report. J Clin Diagn Res. 2013;7:358-360.

[7] Gedik E, Girgin S, Aldemir M, Keles C, Tuncer M, Aktas A. Non-traumatic splenic rupture: report of seven cases and review of the literature. Gastroenterology. 2008 ;14:6711-6716.

[8] Lavrenkov K, Krepel-Volsky S, Levi I, Ariad S. Low dose palliative radiotherapy for splenomegaly in hematologic disorders. Leuk Lymphoma. 2011;53:430-434.

[9] Habermann TM, Rai K. Historical treatments of in hairy cell leukemia, splenectomy and interferon: past and current uses. Leuk Lymphoma. 2011;52:18-20.

[10] Else M., Dearden C.E., Matutes E., Garcia Talavera J., Rohatiner A.Z., Johnson S.A., O'Connor N.T., Haynes A., Osuji N., Forconi F., Lauria F. \& Catovsky D. Long term follow up of 233 patients with hairy cell leukaemia, treated initially with pentostatin or cladribine, at a median of 16 years from diagnosis. British Journal of Haematology,2009; 145, 733-740.

[11] Grever M.R. How I treat hairy cell leukemia. Blood.2010; 115, 21-28.

[12] Matutes E, Martínez-Trillos A, Campo E. Hairy cell leukaemia-variant: Disease features and treatment. Best Pract Res Clin Haematol. 2015 Dec;28(4):253-63.

[13] Robak T, Matutes E, Catovsky D, Zinzani PL, Buske C., ESMO Guidelines Committee. Hairy cell leukaemia: ESMO Clinical Practice Guidelines for diagnosis, treatment and followup. Ann. Oncol. 2015 Sep;26 Suppl 5:v100-7. Else M, Dearden CE, Matutes E, et al. Long- term follow-up of 233 patients with hairy cell leukaemia, treated initially with pentostatin or cladribine, at a median of 16 years from diagnosis. Br J Haematol. 2009; 145(6):733-740.

[14] Naing PT, Acharya U. Cancer, Leukemia, Hairy Cell.StatPearls [Internet]. Treasure Island (FL): StatPearls Publishing; 2018 Jan-.2018 May

[15] Rosenberg JD, Burian C, Waalen J, Saven A. Clinical characteristics and long-term outcome of young hairy cell leukemia patients treated with cladribine: a single-institution series. Blood. 2014;123(2):177-183.

[16] Golomb HM. Fifty years of hairy cell leukemia treatments. Leuk Lymphoma. 2011;52(Suppl 2):3-5.

[17] Grever MR. Hairy cell: young living longer but not cured. Blood. 2014;123(2):150-151.

[18] Cornet E, Delmer A, Feugier P, et al.; French Society of Haematology. Recommendations of the SFH (French Society of Haematology) for the diagnosis, treatment and follow-up of hairy cell leukaemia. Ann Hematol. 2014; 93(12) :1977-1983.

[19] Tadmor T. Purine analog toxicity in patients with hairy cell leukemia. Leuk Lymphoma. 2011;52(Suppl 2):38-42.

[20] Cooley L, Dendle C, Wolf J, et al. Consensus guidelines for diagnosis, prophylaxis and management of Pneumocystis jirovecii pneumonia in patients with haematological and solid malignancies, 2014. Intern Med J. 2014;44(12b):1350-1363.

[21] Buzelé R, Barbier L, Sauvanet A, et al. Medical complications following splenectomy. J Visc Surg.2016;153(4):277-86.

[22] Di Sabatino A, Carsetti R, Corazza GR. Postsplenectomy and hyposplenic states. Lancet. 2011;378(9785):86-97. doi: 10.1016/ S01406736(10)61493-6.

Citation: Vladimir Milosavljević, Boris Tadić, Nikola Grubor, Maja Dimić Ćumič, Slavko Matić, White Spleen in Hairy Cell Leukemia - Case Report and Review of the Literature. ARC Journal of Clinical Case Reports. 2019; 5(1): 1-5. doi:dx.doi.org/10.20431/2455-9806.0501001.

Copyright: (C) 2019 Authors. This is an open-access article distributed under the terms of the Creative Commons Attribution License, which permits unrestricted use, distribution, and reproduction in any medium, provided the original author and source are credited. 